\title{
Anal Necrosis, CTCAE
}

National Cancer Institute

\section{Source}

National Cancer Institute. Anal Necrosis, CTCAE. NCI Thesaurus. Code C143278.

A disorder characterized by a necrotic process occurring in the anal region. 